\title{
MATERNAL AND PERINATAL OUTCOME IN MULTIFOETAL GESTATION
}

\author{
Sonal Jain'1, Vaishali Jain², Laxmi Maru \\ ${ }^{1}$ Assistant Professor, Department of Obstetrics and Gynaecology, PCMS and RC, Bhopal, Madhya Pradesh. \\ ${ }^{2}$ Consultant, Department of Obstetrics and Gynaecology, Mahaveer Hospital, Indore, Madhya Pradesh. \\ ${ }^{3}$ Ex-HOD, Department of Obstetrics and Gynaecology, MGMMC, Indore, Madhya Pradesh.
}

ABSTRACT
BACKGROUND
Recently, the rate of multiple-gestation pregnancies has grown over the last few decades due to increased use of in-vitro
fertilisation and ovulation induction techniques. Multiple pregnancy is considered as high risk due to associated high maternal
morbidity and perinatal mortality in comparison with singleton pregnancies. Multiple pregnancies pose a number of unique
challenges such as discordant growth abnormalities, intrauterine demise, preterm premature rupture of membranes or premature
delivery of one or both twins. All adverse outcomes of pregnancy including mortality are more likely in multiples compared with
singleton pregnancies, and associated risks increase in higher order multiples. Hence, this study was done to study maternal and
perinatal outcome in multifoetal gestation.

\section{MATERIALS AND METHODS}

The study was carried out in the Department of Obstetrics and Gynaecology, Mahatma Gandhi Memorial Medical College and Maharaja Yashwant Rao Hospital, Indore from January 2013 to December 2013. This is a case series, which comprises a total of 142 cases of multiple foetal pregnancies. All multifoetal pregnancy with gestational age of more than 20 weeks were included in the study, either twins, triplets or quadruplets. The cases with singleton pregnancy or twins with foetal reduction were excluded in the study.

\section{RESULTS}

Incidence of multifoetal gestation was about $1.38 \%$. Most (88\%) of the patients were in the age group of 20 - 30 yrs. Correlation with ovulation induction was found in $15.5 \%$ of the patients. $78.87 \%$ were dichorionic-diamniotic, $13.38 \%$ were monochorionicdiamniotic and $4.9 \%$ were monochorionic-monoamniotic. Incidence of moderate PIH was $14.08 \%$ and severe PIH was $10.56 \%$ in multifoetal pregnancies in our study. Three patients $(2.11 \%)$ had eclampsia and $18(12.67 \%)$ were pre-eclamptic. Incidence of severe anaemia (haemoglobin $<7 \mathrm{gm} \%$ ) was 4.92\%, moderate anaemia (haemoglobin 7 - 9 gm\%) was 19.71\%, mild anaemia (haemoglobin $9-11 \mathrm{gm} \%$ ) was 50\% in our study. In our study, the distribution of presentation of first and second twins were as follows: $54.93 \%$ were cephalic-cephalic, $13.38 \%$ were cephalic-breech, $11.97 \%$ were breech-cephalic, $12.68 \%$ were breech-breech and $7.04 \%$ were presentation other than mentioned above. The incidence of caesarean section being 30.28\% for first and 31.69\% for second twin. $60.56 \%$ of first and $52.11 \%$ of second twin had cephalic vaginal delivery and $9.15 \%$ and $15.49 \%$ of first and second twin respectively had assisted breech delivery. 3 patients required section for second foetuses for obstructed labour after delivery of first foetus. In our study $4.22 \%$ delivered at less than 28 weeks of gestation, $19.72 \%$ delivered between 28 and 34 weeks, $19.01 \%$ were in gestational age from 34 to 37 weeks and $37.30 \%$ were 37 weeks or more. Total preterm birth rate being $51 \%$ (less than 37 weeks). The incidence of PROM is $13.38 \%$. Low birth weight and low APGAR score were more common in higher order births as all 4 foetuses in quadruplets required NICU admissions, while most of foetuses born out of triplets were underweight. In our study, $40.14 \%$ of first and $44.37 \%$ of second twin had an APGAR score of less than seven at one minute and 13.38\% of first and $23.94 \%$ of second foetus had an APGAR score of less than seven at five minutes (including stillbirths). 15.22\% of first and $17.65 \%$ of second foetus required admission to NICU. Total incidence of NICU admissions among multifoetal gestation in our study is $33.9 \%$. In our study $6.34 \%$ of first, $13.38 \%$ of second, $25 \%$ of third foetuses were stillborn. Incidence of PPH $(7.04 \%)$ is high, but could be prevented with active alert and vigorous management. The incidence of APH in our study was $3.52 \%$.

\section{CONCLUSION}

In mothers, there is increased risk of hypertension anaemia. They are more prone to malpresentation and increased rate of caesarean sections. Women with multifoetal gestation are more prone to PPH and PROM. Since women with more than one foetus deliver at early gestational age, babies born are preterm and low birth weight, low APGAR require more admissions to NICU.

\section{KEYWORDS}

Multifoetal Gestation, Maternal Outcome, Perinatal Outcome, LBW (Low Birth Weight), APGAR, NICU.

HOW TO CITE THIS ARTICLE: Jain S, Jain V, Maru L. Maternal and perinatal outcome in multifoetal gestation. J. Evolution Med. Dent. Sci. 2018;7(18):2281-2284, DOI: 10.14260/jemds/2018/512

'Financial or Other Competing Interest': None.

Submission 19-03-2018, Peer Review 14-04-2018,

Acceptance 20-04-2018, Published 30-04-2018.

Corresponding Author:

Dr. Vaishali Jain,

Consultant, Department of Obstetrics and Gynaecology,

Mahaveer Hospital, Indore, Madhya Pradesh.

E-mail:dr_vaishalijain@yahoo.com

DOI: $10.14260 /$ jemds $/ 2018 / 512$

\section{BACKGROUND}

As the multifoetal gestation is associated with increased maternal, perinatal and neonatal complication, thus this study is undertaken to evaluate the maternal and perinatal outcome in multifoetal gestation, so that the results of the study can be further utilised to continue the expansion for vision of the future. 


\section{MATERIALS AND METHODS}

This is a case series, which comprises a total of 142 cases of multiple foetal pregnancies. All multifoetal pregnancy with gestational age of more than 20 weeks were included in the study, either twins, triplets or quadruplets. The cases with singleton pregnancy or twins with foetal reduction were excluded in the study. New-borns weighing less than $2500 \mathrm{~g}$ were classified as low birth weight and those weighing less than $1500 \mathrm{~g}$ as very low birth weight.

\section{RESULTS}

Incidence of multifoetal gestation was about $1.38 \%$. Most of multifoetal pregnancies occurred in primigravidas (53.5\%). Most (88\%) of the patients were in the age group of $20-30$ yrs. Correlation with ovulation induction was found in $15.5 \%$ of the patients (Table No. 1).

\begin{tabular}{|c|c|c|c|c|c|c|c|c|}
\hline & \multicolumn{4}{|c|}{ Age (Years) } & \multicolumn{2}{c|}{ Parity } & \multicolumn{2}{c|}{$\begin{array}{c}\text { H/O } \\
\text { Ovulation } \\
\text { Induction }\end{array}$} \\
\hline & $\mathbf{2 0}$ & $\begin{array}{c}\mathbf{2 0 -} \\
\mathbf{2 4}\end{array}$ & $\begin{array}{c}\mathbf{2 5 -} \\
\mathbf{2 9}\end{array}$ & $>\mathbf{3 0}$ & $\begin{array}{c}\text { Primi- } \\
\text { para }\end{array}$ & $\begin{array}{c}\text { Multi- } \\
\text { para }\end{array}$ & Yes & No \\
\hline $\begin{array}{c}\text { Number } \\
(142)\end{array}$ & 4 & 78 & 48 & 12 & 76 & 66 & 19 & 123 \\
\hline $\begin{array}{c}\% \\
(100 \%)\end{array}$ & $2.81 \%$ & $54.9 \%$ & $33.8 \%$ & $8.4 \%$ & $53.5 \%$ & $46.5 \%$ & $13.4 \%$ & $86.6 \%$ \\
\hline
\end{tabular}

Table 1. Distribution of Multifoetal Gestation in Diff Age GRP and Parity

$78.87 \%$ were dichorionic-diamniotic, $13.38 \%$ were monochorionic-diamniotic and $4.9 \%$ were monochorionicmonoamniotic.

Incidence of severe anaemia (Haemoglobin $<7 \mathrm{gm} \%$ ) was $4.92 \%$, moderate anaemia (Haemoglobin 7 - 9 gm\%) was $19.71 \%$, mild anaemia (Haemoglobin 9 - 11 gm\%) was 50\% in our study. Incidence of severe Gestational HTN was $7.75 \%$ and mild Gestational HTN was $10.56 \%$ in our study. $2.11 \%$ had eclampsia and $12.67 \%$ were pre-eclamptic. $4.22 \%$ delivered at less than 28 weeks of gestation, 19.72\% delivered between 28 and 34 weeks, $19.01 \%$ were in gestational age from 34 to 37 weeks. The incidence of PROM was $13.38 \%$. Incidence of PPH was (7.04\%). The incidence of APH in our study was $3.52 \%$ (Table No. 2).

\begin{tabular}{|c|c|c|}
\hline Maternal Complications & Number & $\%$ \\
\hline Mild anaemia & 71 & $50 \%$ \\
\hline Moderate anaemia & 28 & $19.71 \%$ \\
\hline Severe anaemia & 7 & $4.92 \%$ \\
\hline Mild Gest. HTN & 15 & $10.56 \%$ \\
\hline Severe Gest. HTN & 11 & $7.75 \%$ \\
\hline Preeclampsia & 18 & $12.67 \%$ \\
\hline Eclampsia & 3 & $2.11 \%$ \\
\hline Less than 28 weeks & 6 & $4.22 \%$ \\
\hline Early preterm $(28-34 \mathrm{wks})$ & 28 & $19.72 \%$ \\
\hline Late preterm (34 - $37 \mathrm{wks})$ & 27 & $19.01 \%$ \\
\hline PROM & 19 & $13.38 \%$ \\
\hline Oligohydramnios & 10 & $7.04 \%$ \\
\hline Polyhydramnios & 5 & $3.52 \%$ \\
\hline $\mathrm{APH}$ & 5 & $3.52 \%$ \\
\hline $\mathrm{PPH}$ & 10 & $7.04 \%$ \\
\hline
\end{tabular}

$54.93 \%$ were cephalic-cephalic, $13.38 \%$ were cephalicbreech, $11.97 \%$ were breech-cephalic, $12.68 \%$ were breechbreech and $7.04 \%$ were presentation other than above. The incidence of caesarean section being $30.28 \%$ for first and $31.69 \%$ for second twin. $69.71 \%$ of first and $68.30 \%$ of second foetus were delivered vaginally. 3 patients required section for second foetuses for obstructed labour after delivery of first foetus (Table No. 3 ).

\begin{tabular}{|c|c|c|c|c|c|}
\hline & \multicolumn{3}{|c|}{ Presentation } & Mode of Delivery \\
\hline & Cephalic & Breech & Others & Vaginal & LSCS \\
\hline $\begin{array}{c}\text { Foetus } \\
1(142)\end{array}$ & 104 & 37 & 1 & 99 & 43 \\
& $73.23 \%$ & $26.05 \%$ & $0.7 \%$ & $69.71 \%$ & $30.28 \%$ \\
\hline $\begin{array}{c}\text { Foetus } 2 \\
(142)\end{array}$ & 98 & 38 & 6 & 97 & 45 \\
\hline $\begin{array}{c}\text { Foetus 3 } \\
(4)\end{array}$ & $50 \%$ & $26.76 \%$ & $4.22 \%$ & $68.30 \%$ & $31.69 \%$ \\
\hline $\begin{array}{c}\text { Foetus 4 } \\
(1)\end{array}$ & - & - & - & 3 & 1 \\
\hline \multicolumn{7}{|c|}{ Table 3. Presentation and Mode of Delivery } \\
\hline
\end{tabular}

$67.12 \%$ of foetuses had birth weight between 2.5 and 1.5 $\mathrm{kg}$ (low birth weight). $18.34 \%$ had birth weight between 1.5 $1 \mathrm{~kg}$ and a total of $8.65 \%$ had birth weight less than $1 \mathrm{~kg}$. The average birth weight of first and second foetus in our study was 1.85 and $1.71 \mathrm{~kg}$ respectively (Table No. 4).

\begin{tabular}{|c|c|c|c|c|c|c|c|c|}
\hline \multirow{2}{*}{$\begin{array}{c}\begin{array}{c}\text { Birth } \\
\text { Weight }\end{array} \\
>2.5 \mathrm{~kg} \\
\end{array}$} & \multicolumn{2}{|c|}{ First Foetus } & \multicolumn{2}{|c|}{$\begin{array}{l}\text { Second } \\
\text { Foetus }\end{array}$} & \multicolumn{2}{|c|}{$\begin{array}{l}\text { Third } \\
\text { Foetus }\end{array}$} & \multicolumn{2}{|c|}{\begin{tabular}{|c|} 
Total \\
Number of \\
Foetuses
\end{tabular}} \\
\hline & 12 & $2.91 \%$ & 5 & $3.52 \%$ & - & - & 17 & $5.88 \%$ \\
\hline $2.5-1.5 \mathrm{~kg}$ & 101 & $71.12 \%$ & 93 & $65.49 \%$ & 4 & $100 \%$ & 194 & $67.12 \%$ \\
\hline $1.5-1 \mathrm{~kg}$ & 19 & $13.38 \%$ & 29 & $20.42 \%$ & - & - & 53 & $18.34 \%$ \\
\hline $\begin{array}{c}\text { Less Than } \\
1 \mathrm{~kg}\end{array}$ & 10 & $7.04 \%$ & 15 & $10.56 \%$ & - & - & 25 & $8.65 \%$ \\
\hline \multicolumn{9}{|c|}{ Table 4. Birth Weight } \\
\hline
\end{tabular}

$13.38 \%$ of first and $23.94 \%$ of second foetus had an APGAR score of less than seven at five minutes (including stillbirths). All third and fourth foetuses had APGAR less than 7 at 5 minutes. $15.22 \%$ of first and $17.65 \%$ of second foetus required admission to NICU. Total incidence of NICU admissions among multifoetal gestation in our study is $33.9 \%$.

In our study $6.34 \%$ of first, $13.38 \%$ of second, $25 \%$ of third foetuses were stillborn. Overall, incidence of stillbirth was $10.03 \%$ (Table No. 5).

\begin{tabular}{|c|c|c|c|}
\hline $\begin{array}{c}\text { APGAR less than 7 } \\
\text { at 5 Mins }\end{array}$ & Foetus 1 & Foetus 2 & Foetus 3 \\
\hline Number & 19 & 34 & 2 \\
\hline Percentage & $13.38 \%$ & $23.94 \%$ & $100 \%$ \\
\hline \multicolumn{4}{|c|}{ Table 5. APGAR Scores } \\
\hline
\end{tabular}

$15.22 \%$ of first and $17.65 \%$ of second foetus required admission to NICU. Total incidence of NICU admissions among multifoetal gestation in our study is $33.9 \%$ (Table No. 6).

\begin{tabular}{|c|c|c|c|}
\hline & $\begin{array}{c}\text { No. of NICU } \\
\text { Admission }\end{array}$ & NICU Admission & Stillbirth \\
\hline Number & 162 & 98 & 29 \\
\hline Percentage & $56.05 \%$ & $33.91 \%$ & $10.03 \%$ \\
\hline \multicolumn{3}{|c|}{ Table 6. NICU Admissions } \\
\hline
\end{tabular}




\section{DISCUSSION}

Singh et al reported an incidence of $1.81 \%$. Mean maternal age was $25.25 \pm 4.5$ years for twin pregnancies. Twins were seen more in multigravida $(70.7 \%)$ as compared to primigravida (29.3\%) in their study.

Mahendra RP found the incidence of multiple deliveries was 1.9 per 1000 births.

The mean maternal age at presentation was 26 years for both twins and triplets. Most of them were multipara 70 (51\%). Only 3 cases conceived by ovulation induction in their study.

Gundu V et al reported 3\% incidence of twins. The incidence of twin gestation in the age group of 18-22 years was $41 \%$, between $23-25$ years was $32 \%$ and between $26-29$ years was $21 \%$. Twin gestation cases reported in age group 30 years and above are $6 \%$. This shows maximum cases were in the age group of 18-20 years and next were between age group of 23-25 years.

Katke RD reported twin and triplet pregnancy rates were $1.355 \%$ and $0.02 \%$ respectively. Had the maximum number of patients in the age group of 20 - 30 years (90.76), maximum number of patients were primipara $(49.23 \%)$ followed by second parity (35.38 \%) and third parity (14.61\%).

Most of the patients had conceived spontaneously (94.62\%).

$\mathrm{RN} \mathrm{Su}$ et al showed a rate of $1.7 \%$ of multiple pregnancies.

Hanumaiah et al reported maximum incidence $(42 \%)$ of twinning in the age group of $21-25$ years.

In Sheela's series, $52 \%$ patients with multiple gestations were multigravida and $48 \%$ were primigravida.

Vogel et al reported $87.3 \%$ of women with multifoetal pregnancy were in the age group of 18 - 35 yrs., whereas $10.3 \%$ of age group of more than $35 \mathrm{yrs}$.

In our study the incidence of multifoetal gestation is $1.38 \%$, i.e. 142 pregnancies were multifoetal gestation out of overall 10,277 pregnancies occurring in a year in accordance with other known studies, out of which $97.18 \%$ were twins (137 twins or 174 twin babies), 2.11\% were triplets (3 or 9 triplet babies) and $0.70 \%$ ( 1 or 4 quadruplet babies) were quadruplets. In our study $54.9 \%$ were in the age group of 20 to 25 years, $33.8 \%$ were in the age group of 25 to 29 years. Thus $88 \%$ were between 20 to 30 years, which is similar to other studies and $53.5 \%$ were primigravidas. $13.4 \%$ conceived with ovulation induction.

Singh L1- The incidence of preterm labour was $74.7 \%$. Anaemia was found in 33 twin pregnancies (44\%). Gestational hypertension comprised 7\%, preeclampsia $11 \%$ and eclampsia $6 \%$ of patients. In this study, no difference was seen in the incidence of APH between the two study groups (1.33\% in both the groups). Incidence of PROM in this study was $10.67 \%$ in twin pregnancies. Hydramnios has been recorded in 8 twin pregnancies (10.67\%). Incidence of PPH among twin gestation was 10 (13.33\%).

Gundu V ${ }^{2}$ reported incidence of anaemia was 40\%, preeclampsia was $22 \%$, gestational HTN was $10 \%$, eclampsia $1 \%$, hydramnios $5 \%$, placenta previa $1 \%$ and preterm labour was $30 \%$.

Katke $\mathrm{RD}^{3}$ reported preterm labour in $48.461 \%$ and $14.615 \%$ developed PIH, $11.538 \%$ patients had PROM, Polyhydramnios in $3.846 \%$ patients, $1.538 \%$ patients had abruption and $1.538 \%$ patients had $\mathrm{PPH}$.
Hanumaiah et $\mathrm{al}^{4}$ found $73.8 \%$ of twins delivered before 37 weeks.

As per Vogel incidence of early preterm birth $(>32$ weeks) was $6.1 \%$, moderate preterm birth (32 - 33 weeks) was $5.8 \%$ and late preterm birth (34 - 37 weeks) was $23.2 \%$. Total incidence of preterm birth $<37$ weeks was $35.2 \%$. Incidence of severe anaemia with $\mathrm{Hb}<7 \mathrm{gm} \%$ was $2.1 \%$.

Sheela et $\mathrm{al}^{5}$ reported the rate of preterm labour less than 37 weeks to be $62 \%$, severe preeclampsia to be $34 \%$, eclampsia to be $2 \%$ and the incidence of anaemia was $22 \%$ in multifoetal gestation. Among multifoetal gestation, $16 \%$ cases had PPH and 14\% had PROM.

In our study $19.72 \%$ delivered between 28 and 34 weeks, $19.01 \%$ were in gestational age from 34 to 37 weeks. The incidence of PROM was $13.38 \%$. Only $25.35 \%$ had a haemoglobin of more than $11 \mathrm{gm} \%$. Further $14.08 \%$ had mild gestational HTN, $10.56 \%$ had severe gestational HTN. $2.11 \%$ had eclampsia and $12.67 \%$ were preeclamptic. Incidence of PPH was $7.04 \%$.

Singh $\mathrm{L}$ et $\mathrm{al}^{1}$ found the most common presentation was vertex for both the twins (48\%) followed by 1 st breech second vertex (20\%). Next in order was 1st vertex and 2nd breech (13.33\%) and both breech (8\%). Most of twins were diamniotic-dichorionic (65\%). Spontaneous vaginal delivery was seen in $62.67 \%$ of twins.

Mahendra RP6 reported the commonest intrapartum foetal presentation was vertex-vertex 85 (61\%) cases followed by vertex-breech $20(14.3 \%)$ cases, breech-vertex $18(13 \%)$ cases, breech-breech 11 (8\%) cases and vertextransverse $5(3.5 \%)$ cases. There were $93(67 \%)$ dichorionic twins and 46 (33\%) monochorionic twins. 54\% and 52\% of first and second twins were delivered vaginally. $46 \%$ of first and $48 \%$ of second twins were delivered by caesarean section respectively.

Most common combination of presentation of twins in a study by Gundu V (2017)2 was Vertex-Vertex (65\%) followed by Vertex-Breech (17\%), Breech-Breech (7\%) and BreechVertex (5\%). 60\% delivered vaginally and $40 \%$ required caesarean section.

Katke $\mathrm{RD}^{3}$ reported vertex-vertex were the most common presentation (57.812\%), vertex-breech and breech-vertex being the second most common, both occurring with equal frequency accounting for $4.687 \% .53 .125 \%$ of twin 1 and $50 \%$ of twin 2 delivered vaginally, and LSCS was required for $46.875 \%$ of twin 1 and $50 \%$ of twin 2 . Among the triplets, both sets required LSCS.

Sheela et $\mathrm{al}^{5}$ found vertex-vertex $34 \%$, vertex-breech $22 \%$, breech-vertex $6 \%$ and breech-breech $6 \%$. Their study had a caesarean section rate of $34 \%$. In our study, $73.24 \%$ of first and $69.01 \%$ of second twin had cephalic presentation, respectively. $26.05 \%$ and $26.76 \%$ of first and second twin were breech, respectively. The distribution of foetal presentations among multifoetal gestation was as cephaliccephalic 54.93\%, cephalic-breech $13.38 \%$, breech-cephalic $11.97 \%$, breech-breech $12.68 \%$ and others $7.04 \%$. In our study, $60.56 \%$ of first and $52.11 \%$ of second twin had normal cephalic vaginal delivery, $9.15 \%$ of first and $15.49 \%$ of second twin had assisted breech delivery. Rate of caesarean section was $30.28 \%$ and $31.69 \%$ for first and second twin respectively. $25 \%$ of third foetus were delivered by cephalic vaginal delivery, $25 \%$ by assisted breech and $50 \%$ by caesarean section. 
There was no increased risk of congenital malformations in the studies by RN Su, et al. ${ }^{7}$ Katke RD ${ }^{3}$ found the percentage of congenital anomalies was found to be $1.562 \%$ in their study. In our study, the incidence of congenital malformations was $0.1 \%$.

Singh et al ${ }^{1-}$ LBW was seen in $78.67 \%$ twins. NICU admissions were required for $34.67 \%$ of twins. First baby of twin required NICU admission $29.33 \%$ and second baby in $40 \%$. Most common cause of NICU admissions was prematurity and LBW.

Mahendra $\mathrm{RP}^{6}$ reported the average birth weight of first twin was 2100 grams and of second twin was 2040 grams. There were a total of 27 ( 96.4 per 1000 births) perinatal deaths, which included 22 neonatal deaths and 5 stillbirths.

Gundu V2 in their study, $12.5 \%$ babies were with birth weights above $2.6 \mathrm{~kg}$, 30\% babies were weighing between 2.1 and $2.5 \mathrm{~kg}, 31 \%$ babies were weight between $1.6 \mathrm{~kg}$ and $2 \mathrm{~kg}$, $23 \%$ babies were weighing between 1 and $1.5 \mathrm{~kg}$. Less than 1 $\mathrm{kg}$ babies were $6.5 \%$. Perinatal mortality was $100 \%$ in babies weighing less than $1 \mathrm{~kg}$.

Katke RD 3 - The mean weight for twin 1 being 1929 grams with SD 0.4897 and for twin 2 being 1868 grams. The twin 2 $(28.22 \%)$ has greater percentage of NICU admission versus the twin $1(25 \%)$.

Mean birth weight of foetuses in multifoetal twin gestation was $2.35 \mathrm{~kg}$, whereas mean birth weight by Vogel. ${ }^{8}$ He observed 5 minutes APGAR $<7$ in $10.9 \%$ twin pregnancy. The incidence of admission to NICU was $28.9 \%$ and rate of stillbirth among twins was $4 \%$. Sheela et al ${ }^{5}$ reported $27.17 \%$ of foetuses of multifoetal gestation needing NICU admission.

In our study, only $2.91 \%$ of first twin and $3.52 \%$ of second twin had birth weight of $2.5 \mathrm{~kg}$ or more. All the third and fourth foetuses had birth weight between $1-1.5 \mathrm{~kg}$.

$34.60 \%$ and $32.52 \%$ of the total born babies had birth weight between 2 - $2.5 \mathrm{~kg}$ and 1.5 - $2 \mathrm{~kg}$ respectively. $18.34 \%$ had birth weight between $1.5-1 \mathrm{~kg}$ and a total of $8.65 \%$ had birth weight less than $1 \mathrm{~kg}$.

In our study, $13.38 \%$ of first and $23.94 \%$ of second foetus had an APGAR score of less than seven at five minutes (including stillbirths). $15.22 \%$ of first and $17.65 \%$ of second foetus required admission to NICU. Total incidence of NICU admissions among multifoetal gestation in our study was $33.9 \%$. The incidence of stillbirth was $10.03 \%$.

Narongwat et $\mathrm{al}^{9}$ found incidence of TTTS to be $2 \%$ for first and $2 \%$ for second foetus and $4 \%$ of total babies affected.

In our group, there were 3 discordant twins and one pregnancy had evident TTTS.

\section{CONCLUSION}

Multifoetal gestations are at a higher risk for both maternal and perinatal adverse outcomes like preterm labour, gestational hypertension, anaemia, premature rupture of membranes, malpositions, low birth weight, low APGAR scores and more incidence of postpartum haemorrhage. So, multifoetal pregnancies require more antenatal care, early detection of the complications and their treatment and neonatal care facilities.

\section{REFERENCES}

[1] Singh L, Trivedi K. Study of maternal and fetal outcome in twin pregnancy. Int J Reprod Contracept Obstet Gynecol 2017;6(6):2272-8.

[2] Gundu V, Polumuru UD, Hemalatha D, et al. Maternal and perinatal outcome in twin gestation in a referral hospital at Visakhapatnam. IAIM 2017;4(12):153-7. (2)

[3] Katke RD, Thakre NN. Multifetal pregnancy: maternal and neonatal outcome. Obstet Gynecol Int J 2015;3(1):00068. doi: 10.15406/ ogij.2015.03.00068. (3)

[4] Hanumaiah I, Shivanand DR, Visweshwaraiah KG, et al. Perinatal outcome of twin pregnancies at a tertiary care centre, south India. Int J Biol Med Res 2013;4(1):2683-5. (4)

[5] Sheela SR, LakshmiKantha G, Shivaleela A. A prospective study of maternal and perinatal outcome in multifetal gestation in rural India. JEMDS: Journal of Evolution of Medical and Dental Sciences 2013;2(6):607-12. (5)

[6] Mahendra RP, Bikash JK, Deepak D. Maternal and perinatal outcome in multifetal pregnancy: a study at a teaching hospital. American Journal of Public Health Research 2015;3(5A):135-8. doi: 10.12691/ajphr-35A-29. (6)

[7] Su RN, Zhu WW, Wei YM, et al. Maternal and neonatal outcomes in multiple pregnancy: a multicentre study in the Beijing population. Chronic Diseases and Translational Medicine 2015;1(4):197-202. (7)

[8] Vogel JP, Torloni MR, Seuc A, et al. Maternal and perinatal outcomes of twin pregnancy in 23 low and middle-income countries. PLoS One 2013;8(8):e70549.

doi:10.1371/journal.pone.0070549.

[9] Narongwat S, Prapap Y. Pregnancy and perinatal outcomes of twin pregnancies in Prapokklao hospital. Thai Journal of Obs Gyn 2010;18:165-71. (9) 